\title{
Rock physics model of glauconitic greensand from the North Sea
}

\author{
Hossain, Zakir; Mukerji, Tapan; Dvorkin, Jack; Fabricius, Ida Lykke
}

Published in:

Geophysics

Link to article, DOI:

10.1190/geo2010-0366.1

Publication date:

2011

Document Version

Publisher's PDF, also known as Version of record

Link back to DTU Orbit

Citation (APA):

Hossain, Z., Mukerji, T., Dvorkin, J., \& Fabricius, I. L. (2011). Rock physics model of glauconitic greensand from the North Sea. Geophysics, 76(6), E199-E209. https://doi.org/10.1190/geo2010-0366.1

\section{General rights}

Copyright and moral rights for the publications made accessible in the public portal are retained by the authors and/or other copyright owners and it is a condition of accessing publications that users recognise and abide by the legal requirements associated with these rights.

- Users may download and print one copy of any publication from the public portal for the purpose of private study or research.

- You may not further distribute the material or use it for any profit-making activity or commercial gain

- You may freely distribute the URL identifying the publication in the public portal

If you believe that this document breaches copyright please contact us providing details, and we will remove access to the work immediately and investigate your claim 


\title{
Rock physics model of glauconitic greensand from the North Sea
}

\author{
Zakir Hossain $^{1}$, Tapan Mukerji ${ }^{2}$, Jack Dvorkin ${ }^{3}$, and Ida L. Fabricius ${ }^{1}$
}

\begin{abstract}
The objective of this study was to establish a rock physics model of North Sea Paleogene greensand. The Hertz-Mindlin contact model is widely used to calculate elastic velocities of sandstone as well as to calculate the initial sand-pack modulus of the soft-sand, stiff-sand, and intermediate-stiff-sand models. When mixed minerals in rock are quite different, e.g., mixtures of quartz and glauconite in greensand, the Hertz-Mindlin contact model of single type of grain may not be enough to predict elastic velocity. Our approach is first to develop a Hertz-Mindlin contact model for a mixture of quartz and glauconite. Next, we use this Hertz-Mindlin contact model of two types of grains as the initial modulus for a soft-sand model and a stiff-sand model. By using these rock physics models, we examine the relationship between elastic modulus and porosity in laboratory and logging data and link rock-physics properties to greensand diagenesis. Calculated velocity for mixtures of quartz and glau-
\end{abstract}

conite from the Hertz-Mindlin contact model for two types of grains are higher than velocity calculated from the HertzMindlin single mineral model using the effective mineral moduli predicted from the Hill's average. Results of rock-physics modeling and thin-section observations indicate that variations in the elastic properties of greensand can be explained by two main diagenetic phases: silica cementation and berthierine cementation. These diagenetic phases dominate the elastic properties of greensand reservoir. Initially, greensand is a mixture of mainly quartz and glauconite; when weakly cemented, it has relatively low elastic modulus and can be modeled by a Hertz-Mindlin contact model of two types of grains. Silica-cemented greensand has a relatively high elastic modulus and can be modeled by an intermediate-stiff-sand or a stiff-sand model. Berthierine cement has different growth patterns in different parts of the greensand, resulting in a soft-sand model and an intermediate-stiff-sand model.

\section{INTRODUCTION}

Greensands are sandstones composed of a mixture of stiff clastic quartz grains and soft glauconite grains. Glauconite grains are porous and composed of aggregates of iron-bearing clay. Porosity in this sediment is found at two scales: macroporosity between grains and microporosity within grains (Figure 1). Greensand petroleum reservoirs occur world-wide, e.g., the mid-Cretaceous Safaniya Sandstone Member in Saudi Arabia (Cagatay et al., 1996), the Lower Cretaceous Glauconitic sandstone in Alberta, Canada (Tilley and Longstaffe, 1984), the Upper Cretaceous Shannon sandstone in Wyoming, USA (Ranganathan and Tye, 1986), a Lower Cretaceous Greensand offshore Ireland (Winn, 1994) and a late Paleocene Greensand in central part of the North Sea (Solymar, 2002; Solymar et al., 2003; Hossain et al., 2009; Hossain et al., 2011a, b;
Stokkendal et al., 2009). However, evaluation of greensand reservoirs has challenged geologists, engineers and petrophysicsts. Glauconite affects the elastic properties, porosity, and permeability of reservoir rocks (Diaz et al., 2003). Glauconite is also ductile (Ranganathan and Tye, 1986), so it can cause nonelastic deformation of greensand (Hossain et al., 2009) and, hence, can affect reservoir quality. Greensands generally show low resistivity in the reservoir zone due to the large amount of bound water in the glauconite, yet free hydrocarbons can be produced because rather than being pore-filling, glauconite is part of the sand-size grains of the framework (Slot-Petersen et al., 1998).

The seismic reflections depend on contrasts in elastic properties; rock-physics modeling allows us to link seismic properties with geologic properties. Avseth et al. (2005) show that rock-physics

\footnotetext{
Manuscript received by the Editor 9 November 2010; revised manuscript received 29 April 2011; published online 13 January 2012.

${ }^{1}$ Technical University of Denmark, Department of Civil Engineering, Lyngby, Denmark. E-mail: zaho@byg.dtu.dk; ilfa@byg.dtu.dk.

${ }^{2}$ Stanford University, Department of Energy Resources Engineering, Stanford, California, USA. E-mail: mukerji@stanford.edu.

${ }^{3}$ Stanford University, Department of Geophysics, Stanford, California, USA. E-mail: dvorkini@stanford.edu.

(C) 2012 Society of Exploration Geophysicists. All rights reserved.
} 
models are particularly useful for testing multiple possible geological scenarios using well logs, and, when integrated with rock texture properties, can be useful for interpreting observed seismic amplitudes away from well control.

Granular-medium rock-physics models include the HertzMindlin contact model (Mindlin 1949); the Walton model (Walton 1987); Digby's model (Digby 1981); the model of Jenkins (Jenkins et al. 2005); the model of Johnson (Norris and Johnson 1997); the

cemented-sand model (Dvorkin and Nur 1996); the soft-sand model (Dvorkin and Nur, 1996); as well as the stiff-sand and intermediate stiff-sand models (Mavko et al., 2009). Some of the existing granular media models are summarized by Wang and Nur (1992). Commonly used granular-medium models for sandstone are the soft-sand and the stiff-sand models (Dvorkin and Nur, 1996; Mavko et al., 2009). These models are used to infer rock microstructure from elastic modulus-porosity relations. Such techniques are conducted by adjusting an effectivemedium theoretical model curve to a trend in the data, assuming that the microstructure of the sediment is similar to that used in the model (Avseth, 2000).

The soft-sand model was introduced by Dvorkin and Nur (1996) for high-porosity sands. The soft-sand model assumes that porosity reduces from the initial sand-pack value due to the deposition of solid matter away from the grain contacts (Figure 2). The soft-sand model line is represented by the modified lower HashinShtrikman bound (Hashin and Shtrikman, 1963; Dvorkin and Nur, 1996), and connects the sandpack porosity endpoint and the pure mineral endpoint. The lower Hashin-Shtrikman bound, which is an isostress model for suspensions, is always the elastically softest way to mix multiple mineral phases. In the soft-sand model, the effective moduli of the initial sand-pack are computed by the Hertz-Mindlin contact theory (Mindlin, 1949; Mavko et al., 2009), whereas the elastic moduli at the zero-porosity end member are defined by the elastic moduli of the minerals. The porosity reduction between these points will be a gradual stiffening of the rock, as smaller grains fill the pore-space between the larger grains.

A counterpart to the soft-sand model is the stiff-sand model. The stiff-sand model assumes that porosity reduces from the initial sand-pack value due to the deposition of cement at the grain contacts (Figure 2). The stiff-sand model line

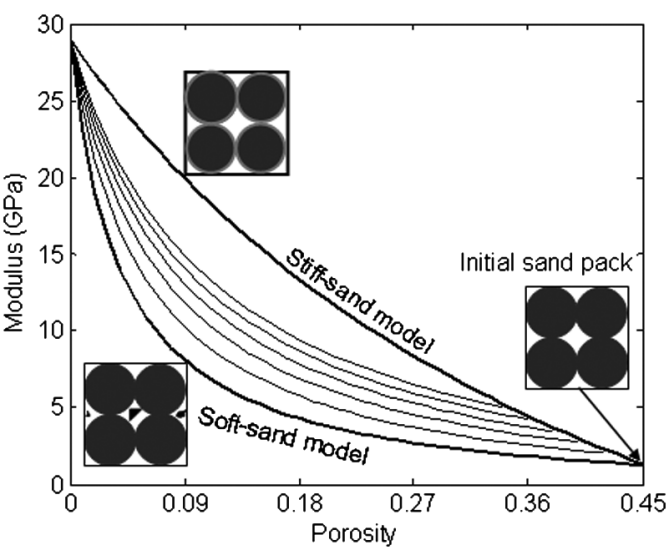

Figure 2. Illustration of the soft-sand model (modified HashinShtrikman lower bound) and stiff-sand model (modified HashinShtrikman upper bound). The curves between the bounds are the intermediate-stiff-sand model that uses the soft-sand model equation with increasing coordination number. is represented by the modified upper Hashin-Shtrikman bound (Hashin and Shtrikman, 1963; Mavko et al., 2009), and connects the initial sand-pack porosity endpoint and the pure mineral endpoint. Like in the soft-sand model, the initial sand-pack modulus of the stiff-sand model is determined by the Hertz-Mindlin theory (Mindlin, 1949), whereas the mineral endpoint is defined by the elastic moduli of the minerals. The porosity reduction from the initial sand-pack will stiffen the rock as the contacts between the grains grow.

The intermediate-stiff-sand model fills the interval between the stiff-sand and soft-sand model (Mavko et al., 2009). This model uses the function from the soft-sand model, but the high-porosity endpoint is situated on the stiff-sand model curve (Figure 2). The easiest way to generate these curves is by simply increasing the coordination number of the Hertz-Mindlin theory in the softsand model (Mavko et al., 2009). The stiff-sand model explains the theoretically stiffest way to add cement with initial sand-pack, while the soft-sand model explains the theoretically softest way to add pore-filling minerals. However, rocks with very little initial 
contact cement are not well described by either the stiff-sand or the soft-sand model. In this case, the intermediate-stiff-sand model can be used because it takes into account the initial cementation effect.

The Hertz-Mindlin contact model (Mindlin 1949) calculates the normal and shear contact stiffnesses of two spherical grains in contact. In this model, grain contacts are first exposed to normal loading, with tangential forces applied afterward. The effective elastic moduli of the granular assembly are then estimated by taking averages of contact forces corresponding to an assumed distribution of strain over all the contacts (e.g. Walton 1987). Several authors (e.g., Goddard, 1990; Bachrach et al., 2000; Zimmer, 2003; Makse et al., 2004) have explained the discrepancies between measured data and predictions from the Hertz-Mindlin contact model. Makse et al. (2004) found that the relation between coordination number and porosity from molecular dynamics simulations usually predicts a lower coordination number than Murphy's empirical relation (Murphy, 1982). Sain (2010) shows using granular dynamics simulations that the cause for the discrepancies between measured data and predictions from Hertz-Mindlin contact models are due to heterogeneities in coordination number and stress distributions in the granular pack. To mitigate the overprediction from effectivemedium models, the modeled effective modulus at the critical porosity is often divided by an ad hoc correction factor, and another ad hoc constant is applied to use the frictionless versions of the contact models combined with unrealistically high coordination numbers (Dutta, 2009). DeGennes (1996) suggests that the Hertz model is not valid for granular media. However, Coste and Gilles (1999) experimentally confirm the validity of the Hertz single contact model.

Still, the Hertz-Mindlin model appears to be the most commonly used contact model for sandstone. Although the Hertz-Mindlin theory is only applicable to perfect elastic contacts of spherical bodies, it works fairly well for sands (Avseth et al., 2005). This model is used to calculate the initial sand-pack modulus of the soft-sand, stiff-sand, and intermediate-stiff-sand models. For the initial sand-pack for sandstone, it is assumed that only quartz grains are packed together, and the normal and shear stiffness are calculated based on the contact of two quartz grains. For rocks with mixed mineralogy, a homogeneous mineral modulus is assumed, typically derived using Hill's average (Hill, 1952). Then the normal and shear stiffnesses are calculated based on the contact of two average-mineralogy grains. However, this is probably only adequate when the moduli of mixed minerals are quite similar. When the mixed minerals are quite different (such as quartz and glauconite) we may lose some of the predictive value (Avseth et al., 2005).

For greensands, the initial sand-pack is a mixture of quartz and glauconite, and because both of them are load-bearing, elastic properties between those of quartz and glauconite are anticipated. To address this, we present a Hertz-Mindlin contact model for mixtures of quartz and glauconite.

The objective of this study is to establish a rock-physics model of North Sea Paleogene greensand. In published work, laboratory ultrasonic measurements have been performed in quartz sandstone (Han, 1986) and shaly sandstone (Marion, 1990), and various theoretical models have been developed (see overview in Mavko et al., 2009). However, rock-physics models for greensand are not well defined yet. Achieving this objective will improve the understanding and interpretation of seismic signatures of greensand. First, our approach is to develop a Hertz-Mindlin contact model for a mixture of quartz and glauconite grains. Next, we use this Hertz-Mindlin contact model of two types of grains as initial modulus for a soft-sand model and a stiff-sand model. Using these rock-physics models, we explore the effect of microstructure on the elastic properties of greensand.

Elastic properties are controlled by a wide range of factors, including porosity, lithology, pore fluids, and pressure. In this study, we superimpose the elastic-modulus-porosity relations of laboratory and logging data on the rock-physics model and finally link the rock-physics properties to greensand diagenesis by thin-section analysis.

\section{CONTACT MODEL FOR MIXTURE OF QUARTZ AND GLAUCONITE GRAINS}

We investigate the effective elastic properties of a granular pack of spheres, for which each pair of grains in contact under normal and tangential load determines the fundamental mechanics. Typically, in granular media models for unconsolidated sand, all grains are taken to be of the same material. Here we consider the contact deformation of two grains made of two different minerals, quartz and glauconite, each with the same radius $R$, to calculate the effective bulk, and shear modulus for a dry pack. The mineral's effective Young's modulus of quartz and glauconite, $E_{\mathrm{Eff}(2)}$ is calculated from the elastic properties of the two minerals as (Johnson, 1985)

$$
E_{\mathrm{Eff}(Q G)}=\left(\frac{1-\nu_{q}^{2}}{E_{q}}+\frac{1-\nu_{g}^{2}}{E_{g}}\right)^{-1}
$$

where $\nu_{q}$, and $E_{q}$ are the Poisson's ratio and Young's modulus of quartz, respectively, and $\nu_{g}$, and $E_{g}$ are the Poisson's ratio and Young's modulus of glauconite, respectively. The relation between Young's modulus $E$, Poisson's ratio $\nu$, and the shear modulus $\mu$ in an isotropic material is $E=2 \mu(1+\nu)$. By using this relationship, equation 1 can be written as

$$
E_{\mathrm{Eff}(Q G)}=\left(\frac{1-\nu_{q}}{2 \mu_{q}}+\frac{1-\nu_{g}}{2 \mu_{g}}\right)^{-1}
$$

where $\mu_{q}$, and $\mu_{g}$ are the shear moduli of quartz and glauconite, respectively. If the material of the two grains are the same, the effective Young's modulus, $E_{\mathrm{Eff}}$ is calculated from the elastic properties of this mineral, and then equation 1 can be written as

$$
\begin{gathered}
E_{\mathrm{Eff}}=\left(2 \frac{1-\nu^{2}}{E}\right)^{-1}=\frac{E}{2\left(1-\nu^{2}\right)}=\frac{2 \mu(1+\nu)}{2\left(1-\nu^{2}\right)}=\frac{\mu}{1-\nu} ; \\
E_{\mathrm{Eff}(Q Q)}=\frac{\mu_{q}}{1-\nu_{q}} \\
E_{\mathrm{Eff}(G G)}=\frac{\mu_{g}}{1-\nu_{g}},
\end{gathered}
$$

where $E_{\operatorname{Eff}(Q Q)}$ is the effective Young's modulus of quartz-quartz contacts, and $E_{\operatorname{Eff}(Q Q)}$ is the effective Young's modulus of glauconite-glauconite contacts. Effective Young's modulus in equation 1 describes exactly the contacts between a quartz and a glauconite grain. For unequal mixtures of quartz and glauconite, 
the effective Young's modulus may be calculated approximately by balancing contacts among quartz-quartz (QQ), quartz-glauconite (QG), and glauconite-glauconite (GG) according to their proportions, and assuming that the contacts are independent of each other (Figure 1b). Denoting the solid volume fractions of quartz as $f_{q}$, and glauconite as $f_{g}$, the effective Young's modulus for a mixture of quartz and glauconite, $E_{\mathrm{Eff}(2)}$ can be approximated as

$$
\begin{aligned}
E_{\mathrm{Eff}(2)}= & f_{q}\left(f_{q} \cdot E_{\mathrm{Eff}(Q Q)}+f_{g} \cdot E_{\mathrm{Eff}(Q G)}\right) \\
& +f_{g}\left(f_{g} \cdot E_{\mathrm{Eff}(G G)}+f_{q} \cdot E_{\mathrm{Eff}(Q G)}\right)
\end{aligned}
$$

$$
\left.E_{\mathrm{Eff}(2)}=f_{q}^{2} \cdot E_{\mathrm{Eff}(Q Q)}+2 f_{g} \cdot f_{q} \cdot E_{\mathrm{Eff}(Q G)}\right)+f_{g}^{2} \cdot E_{\mathrm{Eff}(G G)} .
$$

In the Hertz model of normal compression of the two identical grains, the radius of contact area $a$ is (Mavko et al., 2009)

$$
a=\left[\frac{3 F R(1-\nu)}{8 \mu}\right]^{1 / 3}=\left[\frac{3 F R}{8 E_{\mathrm{Eff}}}\right]^{1 / 3},
$$

where $F$ is the compressing force between the two grains. For two different grains, the radius of the resulting Hertzian contact is

$$
a(2)=\left[\frac{3 F R}{8 E_{\mathrm{Eff}(2)}}\right]^{1 / 3} \text {. }
$$

If $P$ is the effective pressure applied to a dry pack of grains, the external stress applied to the solid phase is $P /(1-\phi)$, where $\phi$ is the porosity of the grain pack. Next, because the surface area of each grain is $4 \pi R^{2}$, the total force applied to a single grain is $4 \pi R^{2} P /(1-\phi)$. This force is distributed among $C$ contacts, where $C$ is the coordination number, which is sometimes related to porosity. Here, we take the $C-\varphi$ relation according to Murphy (1982), though other relations, e.g., from granular dynamics simulations, could also be used. If the effective pressure $P$ is applied to a random, identical-sphere packing, the effective force acting between two particles is (Mavko et al., 2009)

$$
F=\frac{4 \pi R^{2} P}{C(1-\phi)}
$$

If the material only contains one type of grains, the radius of the resulting Hertzian contact is (combining equation 10 and equation 8

$$
a=R\left[\frac{3 \pi P}{2 C(1-\phi) E_{\mathrm{Eff}}}\right]^{1 / 3} .
$$

Now, by combining equation 9 and equation 11, we find the radius of the resulting Hertzian contact for two types of grains made of different elastic materials:

$$
a(2)=R\left[\frac{3 \pi P}{2 C(1-\phi) E_{\mathrm{Eff}(2)}}\right]^{1 / 3} .
$$

If the material only contains one type of grains, the effective bulk modulus of a dry pack is (Mavko et al., 2009)

$$
K_{\mathrm{Eff}}=\left[\frac{C^{2}(1-\phi)^{2} \mu_{s}^{2}}{18 \pi^{2}\left(1-\nu_{s}\right)^{2}} P\right]^{1 / 3}=\left[\frac{C^{2}(1-\phi)^{2} E_{\mathrm{Eff}}^{2}}{18 \pi^{2}} P\right]^{1 / 3}
$$

If the material contains two types of grains, the effective elastic bulk modulus of the dry pack is

$$
K_{\mathrm{Eff}(2)}=\left[\frac{C^{2}(1-\phi)^{2} E_{\mathrm{Eff}(2)}^{2}}{18 \pi^{2}} P\right]^{1 / 3} .
$$

If the material only contains one type of grains, the effective shear modulus of a dry pack is (Mavko et al., 2009)

$$
\mu_{\mathrm{Eff}}=\frac{(5-4 \nu)}{5(2-\nu)}\left[\frac{3 C^{2}(1-\phi)^{2} \mu^{2}}{2 \pi^{2}(1-\nu)^{2}} P\right]^{1 / 3}=\frac{(5-4 \nu) 3 K_{\mathrm{Eff}}}{5(2-\nu)} .
$$

If the material contains two types of grains, the effective shear modulus of a dry pack is

$$
\mu_{\mathrm{Eff}(2)}=\frac{\left(5-4 \nu_{\mathrm{Eff}}\right) 3 K_{\mathrm{Eff}(2)}}{5\left(2-\nu_{\mathrm{Eff}}\right)},
$$

where, $\nu_{\mathrm{Eff}}$ is the effective Poisson's ratio of the grain mixture.

A soft-sand model is a heuristically modified Hashin-Shtrikman lower bound. The bulk $\left(K_{\text {Dry }}\right)$ and shear moduli $\left(G_{\text {Dry }}\right)$ of such dry sand at porosity $\varphi$ can be calculated (Dvorkin and Nur, 1996) as follows

$$
\begin{gathered}
K_{\text {Dry }}=\left[\frac{\phi}{K_{H M}+4 G_{H M} / 3}+\frac{1-\phi}{K+4 G_{H M} / 3}\right]^{-1}-4 G_{H M} / 3 \\
G_{\text {Dry }}=\left[\frac{\phi}{G_{H M}+z}+\frac{1-\phi}{G+z}\right]^{-1}-z \\
z=\frac{G_{H M}}{6}\left[\frac{9 K_{H M}+8 G_{H M}}{K_{H M}+2 G_{H M}}\right]
\end{gathered}
$$

The stiff-sand model (a heuristic modified Hashim-Shtrikman upper bound) is a counterpart to the soft-sand model. The bulk $\left(K_{\text {Dry }}\right)$ and shear $\left(G_{\text {Dry }}\right)$ moduli of such dry sand at porosity $\varphi$ can be calculated (Mavko et al., 2009) as

$$
\begin{gathered}
K_{\text {Dry }}=\left[\frac{\phi}{K_{H M}+4 G / 3}+\frac{1-\phi}{K+4 G / 3}\right]^{-1}-4 G / 3 \\
G_{\text {Dry }}=\left[\frac{\phi}{G_{H M}+z}+\frac{1-\phi}{G+z}\right]^{-1}-z, \\
z=\frac{G}{6}\left[\frac{9 K+8 G}{K+2 G}\right],
\end{gathered}
$$


where $K$ and $G$ are the bulk and shear moduli of grains, respectively; and $K_{H M}$ and $\mu_{H M}$ are, respectively, the effective bulk and shear moduli of the dry grain pack calculated from Hertz-Mindlin theory. For a single type of the grain material, $K_{H M}$ and $\mu_{H M}$ are calculated by using equation 13 and equation 15 , respectively. For two different types of grains, $K_{H M}$ and $\mu_{H M}$ are calculated by using equation 14 and equation 16 , respectively.

\section{GEOLOGICAL SETTING OF NINI FIELD AND DATA AVAILABLE}

Nini field is located in Siri Canyon, which is part of a larger system of submarine canyons in the Paleocene in the NorwegianDanish Basin running in the east-west to northeast-southwest direction toward the Central Graben (Figure 3). The Nini accumulation is defined by a combined structural and stratigraphic trap, the anticlinal structure being induced through salt tectonics. The reservoir consists of sands deposited in the Siri Fairway. The glauconitebearing sandstone in the Nini field was recognized as the Paleocene greensand. The Paleocene greensand is characterized by thick beds of olive-green to greenish gray, very fine to fine-grained, wellsorted sandstone in which both quartz grains and glauconite pellets are part of the load-bearing matrix. Rounded and translucent quartz grains dominate, but the content of glauconite grains is $20 \%-30 \%$ (Schiøler et al., 2007).

A series of log data including compressional wave velocity $\left(V_{\mathrm{P}}\right)$, shear wave velocity $\left(V_{\mathrm{S}}\right)$, and density $(\rho)$, as well as laboratory measured $V_{\mathrm{P}}, V_{\mathrm{S}}, \rho$, and porosity on sixteen 1.5 inch horizontal core plugs are included in this study. These data represent the two greensand formations of the Nini field. The samples have already been used for routine core analysis and were chosen to cover the range of variation in porosity $(25 \%-40 \%)$ and air permeability $(60-1000 \mathrm{mD})$. All cores were cleaned of brine and hydrocarbons by soxhlet extraction with methanol and toluene prior to analysis. Thin sections were prepared from the end of each plug. Backscattered electron micrographs (BSE) from thin sections are also available for this study. The mineralogical composition has been determined by point counting of thin sections (Solymar, 2002). We estimate the glauconite grain bulk modulus to be about $7 \mathrm{GPa}$ and shear modulus to be about $5 \mathrm{GPa}$ (Hossain et al., 2009). The effective mineral moduli are then calculated by using the Voigt-Reuss-Hill average (Mavko et al., 2009), and the effective density is calculated using the arithmetic average. The effective bulk modulus is $33 \mathrm{GPa}$, shear modulus is $29 \mathrm{GPa}$ and density is $2.71 \mathrm{~g} / \mathrm{cm}^{3}$ at $30 \%$ glauconite content. The brine and oil properties were computed by using Batzle and Wang's relations (Batzle and Wang, 1992). We calculate the brine bulk modulus and density to be $2.97 \mathrm{GPa}$ and $1.05 \mathrm{~g} / \mathrm{cm}^{3}$, and the oil bulk modulus and density to be $1.53 \mathrm{GPa}$ and $0.84 \mathrm{~g} / \mathrm{cm}^{3}$.

The ultrasonic P- and S-wave velocities were measured on all dry samples using the pulsetransmission technique with an approximate center frequency of $132 \mathrm{kHz}$. The ultrasonic measurements were done at hydrostatic confining pressure with steps from 1 to $15 \mathrm{MPa}$. The ultrasonic velocities of the samples were calculated from the transit time to travel the sample length. The system delay time was subtracted from the transit time. The system delay time was determined by measuring the transit time on three aluminum plugs of different lengths. The transit times for the P- and S-waves were measured on a digital oscilloscope and saved digitally for a later manual analysis. Using error propagation, the estimated standard deviations, $\sigma$ are as follows: $\sigma\left(V_{\mathrm{P}}\right)<0.05 \mathrm{~km} / \mathrm{s}, \sigma\left(V_{\mathrm{S}}\right)<0.1 \mathrm{~km} / \mathrm{s}$ and $\sigma(\rho)<0.08 \mathrm{~g} / \mathrm{cm}^{3}$. The dry-rock density was calculated from the dry weight and volume of the samples.

We studied the oil- and brine-bearing greensand interval to establish the rock-physics model from the logging data. To correct $V_{\mathrm{P}}$, $V_{\mathrm{S}}$, and density for full brine saturation conditions prior to the rock-physics modeling, we applied Gassmann's fluid substitution method (Gassmann, 1951) in the oil-bearing greensand interval by assuming a homogenous mixture of oil and brine.

\section{HERTZ-MINDLIN MODELING FOR QUARTZ AND GLAUCONITE}

The P- and S-wave velocities calculated by using Hertz-Mindlin contact model for two types of grains are presented in Figure 4. We notice that, in the limit, the Hertz-Mindlin contact model for a single grain type as reported in Mavko et al. (2009) has the same solution as our Hertz-Mindlin model for two types of grains when the fraction of one constituent is one and the other is zero and vice-versa (upper and lower curves in Figure 4). Calculated velocity for mixtures of quartz and glauconite (middle dashed-dot curves in Figure 4) are higher than velocity predicted from averages of $100 \%$ quartz velocity and $100 \%$ glauconite velocity (middle dotted

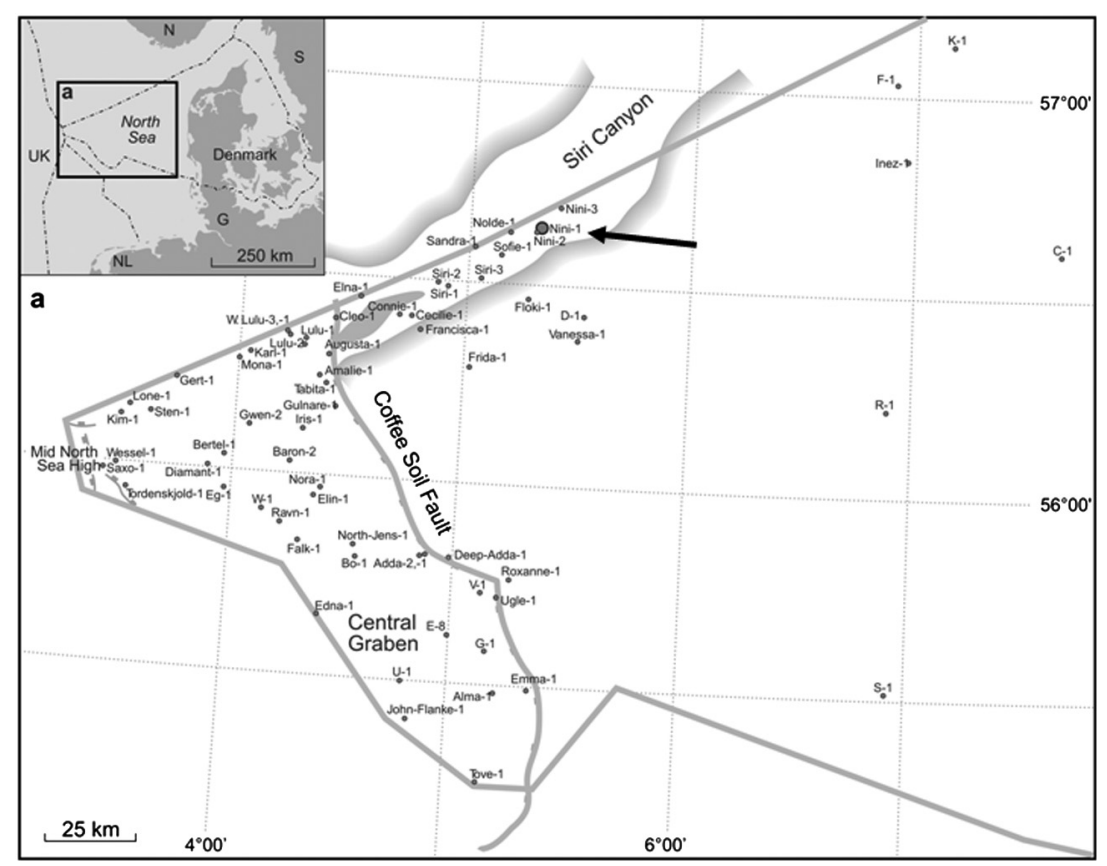

Figure 3. Map showing location of Nini field in the Danish North Sea (arrow). Gray shading on this map indicates the margins of the Siri Canyon; gray shading inside the canyon indicates an area of positive relief within the canyon. Germany $(G)$, Norway $(N)$, Netherlands (NL), Sweden (S), and United Kingdom (UK) (Figure modified after Schiøler et al., 2007). 
curves in Figure 4). Calculated velocity for mixtures of quartz and glauconite (middle dashed-dot curves in Figure 4) are even higher than velocity calculated from the Hertz-Mindlin contact model for a single grain type by using the effective minerals predicted from Hill's average (Hill, 1952) (middle dashed curves in Figure 4). This demonstrates that the Hertz-Mindlin model with two types of grains may not be approximated by the Hertz-Mindlin single mineral model for a mixture of quartz and glauconite.

Next, we verify the Hertz-Mindlin model for two types of grains by laboratory experimental results. Figure 5a represents the experimental results and results from the Hertz-Mindlin model for two types of grains. From the porosity-coordination number relationship given by Murphy (1982) we used coordination number of eight for this calculation. Thin-section analysis shows that this greensand sample is only weakly cemented (Figure 5b). For weakly cemented greensand, the Hertz-Mindlin contact model for two types of grains has good agreement with laboratory measured data.

However, for cemented greensand, the Hertz-Mindlin contact model of two types of grains underestimates the velocity (Figure 6). From the porosity-coordination number relationship given by Murphy (1982), we used a coordination number of eight for this calculation. Due to cementation of greensand, the area of contacts between grains increase, thus to match velocity prediction with experimental results we artificially increase the coordination number to 18 . The Hertz-Mindlin model is designed to describe the properties of precompacted granular rocks (Mavko et al., 2009). Thus one may debate the applicability of the Hertz-Mindlin contact model for

\section{a)}

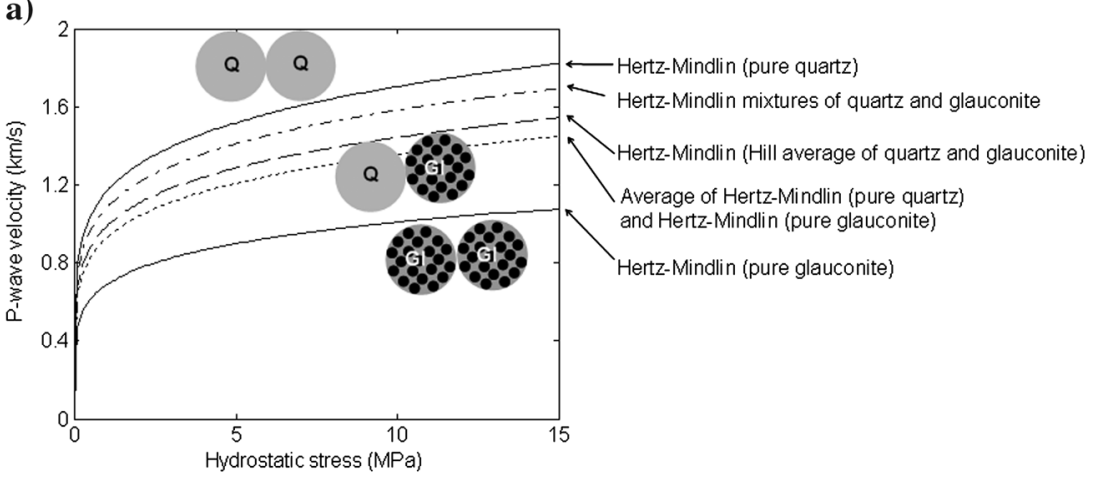

b)

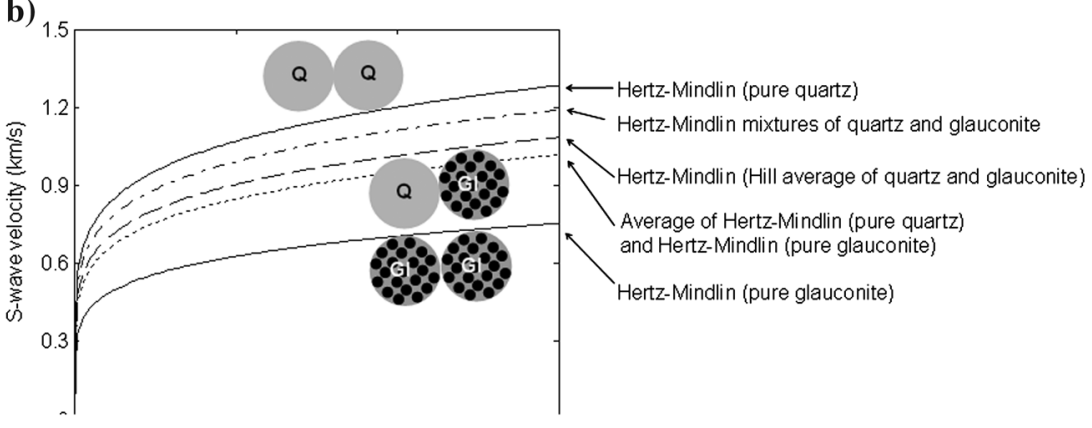

Figure 4. (a) P-wave and (b) S-wave velocity calculated using Hertz-Mindlin contact model with two types of grains. Upper curves are calculated for a quartz fraction of one and glauconite fraction of zero. Lower curves are calculated for a quartz fraction of zero and glauconite fraction of one. The middle dotted curves are the average of the upper and lower curves. The middle dash-dot curves are calculated for $70 \%$ quartz and $30 \%$ glauconite. The middle dashed curves represent the Hill average of minerals to get effective minerals and then the effective minerals used in Hertz-Mindlin single mineral model. cemented samples. The theory behind the model is based on the normal and shear contact stiffness of two spherical grains due to external applied pressure. Cementation of greensand certainly causes a higher contact area. However, when calculating the effecive bulk and shear moduli of a dry sphere pack, the coordination mber to some degree takes into account the shape of the grains Mindlin contact model.

\section{MODELING OF LABORATORY AND LOG DATA}

We used the Hertz-Mindlin contact model for two types of grains to calculate the initial sand-pack modulus for a soft-sand and a stiffsand model. The elastic-modulus-porosity cross plots of laboratory and logging data are presented in Figures 7 and 8. To understand the bserved elastic-modulus difference in greensand, we superimpose model lines on the elastic-modulus-porosity cross-plot. The cs models shown in Figure 7 for laboratory data imply " and "silica cementation" For the compressional modshear modulus, the rock-physics model shown in Figure $7 \mathrm{~b}$ implies that the greensand has no initial contact cementation.

For logging data, the rock-physics model curves shown in Figure 8 also imply that the greensand has two general trends: berthierine cementation and silica cementation. The berthierine cementation trends in Figure 7 and Figure 8 are likely due to the increasing amount of pore-filling minerals in the pore-space between larger grains. These pore-filling minerals have small effect on the elastic modulus but a large effect on the porosity. Hence, the porosity in greensands decreases from initial quartz-glauconite pack porosity due to the increasing amount of pore-filling minerals. The cementation trend goes from the soft-sand model to the stiffsand model. Cementation has a very strong effect on elastic properties and a weaker effect on porosity.

Unlike the laboratory data, the logging data fall into two clusters: one cluster follows the soft-sand model curve, while the other follows the stiff-sand model. Although some data points lie on the intermediate stiff-sand model curves, these data points are few and do not form a cluster.

\section{SILICA AND PORE-FILLING BERTHIERINE CEMENTATION}

BSE images of sixteen greensand samples from two reservoir formations are used for this study. Petrographic thin-section analysis indicates that these Paleocene greensands are well to very well-sorted and dominated by quartz 
grains. However, large volumes of glauconite are present in the samples as well: Greensand from the North Sea Nini field exhibits glauconite volumes in excess of $30 \%$ of the total mineral composition, as determined by quantitative analysis of sixteen thin-sections (Solymar, 2002). These results come from point counting on 500 -cell grids for each thin-section. All greensands are fine-grained, with the average grain size of the detrital quartz between 100 and $200 \mu \mathrm{m}$. BSE images of four greensand samples are shown in Figure 9. We observed marked variations in the character of these BSE images: the upper two images (Figure 9a and 9b) show only weak cementation, whereas the two lower images (Figure 9c and 9d) reveal substantial cementation.

To this end, we can define the two main diagenetic phases in the greensand: silica cementation and berthierine cementation, as illustrated in Figure 10. The silica cement appears in the form of microcrystalline quartz, with crystals about $2 \mu \mathrm{m}$ in diameter, probably formed as an opal rim on the surface of the grains (Figure 10a). Microcrystalline-quartz coating on detrital grains is located at the grain contacts. As a result, this quartz cement acts to stiffen the rock (Stokkendal et al. 2009). Hence, the presence of the microcrystalline quartz cement should have a major effect on the elastic properties of greensand.

The pore-filling berthierine cement is randomly oriented and precipitates in the pores between the large grains (Figure 10b). The main mineralogical difference between these two types of diagenetic phases is in that microcrystallinequartz-cemented samples may contain more $\mathrm{SiO}_{2}$ than berthierine-cemented samples (Stokkendal et al., 2009).

Our next step is to understand the effects of these pore-filling minerals on the elastic properties and porosity of the rock. Along these lines, we observe a correlation between pore-filling berthierine and total porosity, where total porosity of greensand linearly decreases when the amounts of pore-filling berthierine are increased (Figure 11a). We also observe a correlation between sonic velocity and pore-filling berthierine, where velocity linearly increases when the amounts of pore-filling berthierine are increased (Figure 11b). Hence, this thin-section analysis is consistent with our choice of rock-physics models.

\section{DISCUSSION}

We provided a Hertz-Mindlin model for two types of mineral grains. Our modeling results demonstrate that the Hertz-Mindlin model with two types of grains may not be approximated by the Hertz-Mindlin single mineral model. Velocity a)

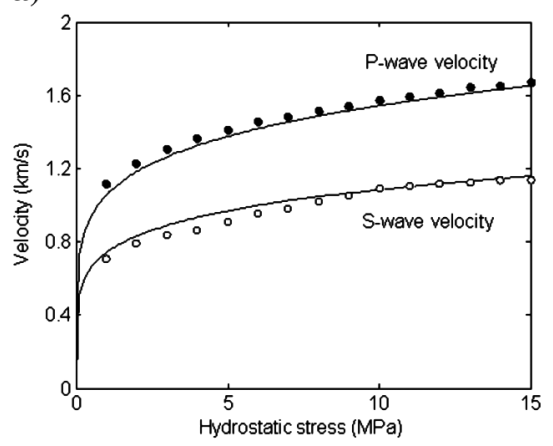

b)

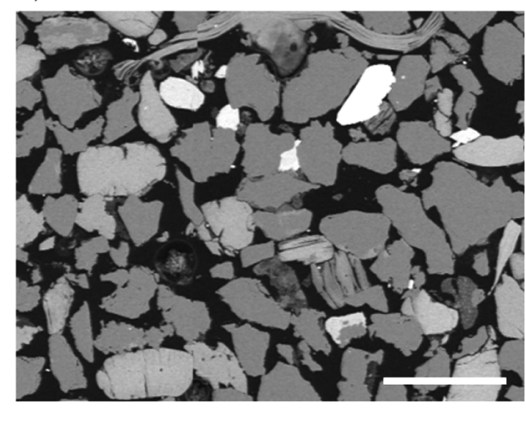

Figure 5. (a) Laboratory measured P-wave velocity (filled circles) and S-wave velocity (open circles) of a weakly cemented greensand and predicted velocity (solid lines) by using the Hertz-Mindlin contact model of two types of grains for 70\% quartz and 30\% glauconite. (b) BSE image of weakly cemented greensand sample.

a)

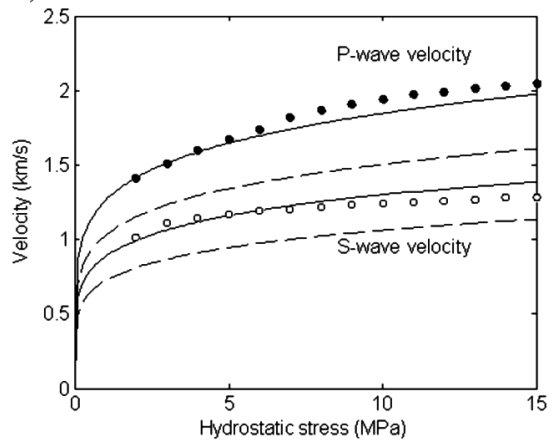

b)

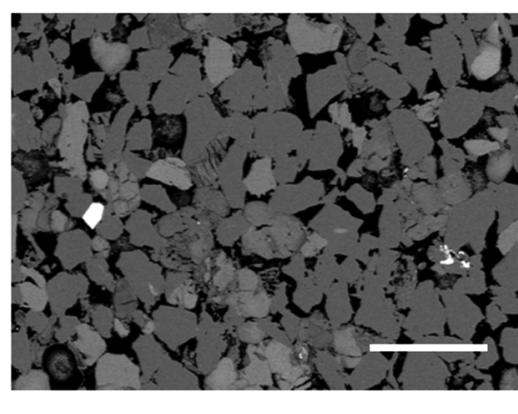

Figure 6. (a) Laboratory measured P-wave velocity (filled circles) and S-wave velocity (open circles) of a cemented greensand and predicted velocity (solid and dashed lines) by using the Hertz-Mindlin contact model of two types of grains for $70 \%$ quartz and $30 \%$ glauconite. Dashed lines represent calculated velocity using a coordination number of eight. Solid lines represent calculated velocity using an artificial coordination number of 18. (b) BSE image of cemented greensand.

a)

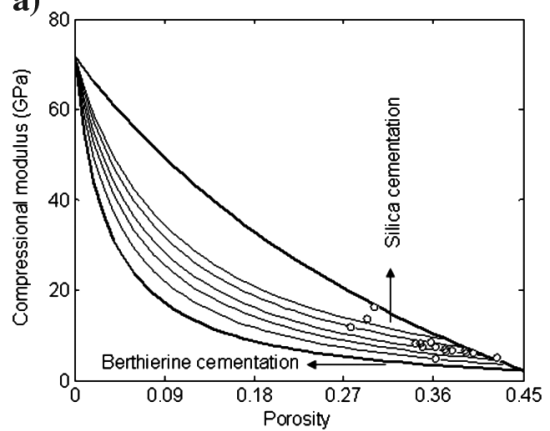

b)

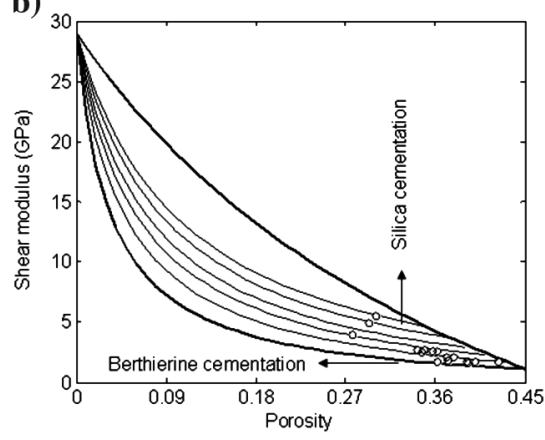

Figure 7. Modeling of laboratory measured greensand samples (a) for compressional modulus and (b) for shear modulus. Model curves represent the soft-sand (lower), stiffsand (upper), and intermediate-stiff-sand (middle) models. "Berthierine cementation" is due to an increasing amount of pore-filling minerals in the pore-space between larger grains. Initial sand-pack modulus of these models was calculated by using the HertzMindlin contact model for two types of grains. 
calculated from the Hertz-Mindlin single mineral model by using effective mineral moduli predicted from the Hill's average (Hill, 1952) of quartz and glauconite are lower than calculated velocity from the Hertz-Mindlin contact model for two types of grains. This is probably due to higher moduli contrasts between quartz and glauconite. So for rocks when mixed minerals are quite different, we may lose some of the predictive value by using the Hertz-Mindlin contact model with single grain type, though a fit to data may be obtained by using an unphysically high coordination number.

We have discussed rock-physics modeling for greensand with emphasis on the effect of pore-filling versus pore-lining cementation. It appears that such texture identification is crucial in the sands under examination: the reservoir zone can produce drastically different seismic responses depending on whether the sands are
Figure 8. Modeling of greensand logging data (a) for compressional modulus and (b) for shear modulus. Model curves are the soft-sand (lower), stiffsand (upper), and intermediate-stiff-sand (middle) models. Berthierine cementation is due to increasing the pore-filling minerals in the pore space between larger grains. Initial sand-pack modulus of these models was calculated by using the HertzMindlin contact model for two types of grains.

Figure 9. BSE images of greensand samples show the variation of microcrystalline-quartz and berthierine cement. Scale bar for the image is $200 \mu \mathrm{m}$. (a) Weakly cemented greensand, with $3.7 \%$ pore-filling berthierine, (b) weakly cemented greensand, with $2.2 \%$ pore-filling berthierine, (c) Microcrystalline-quartz cemented greensand, with pore-filling berthierine of about $8 \%$. (d) Microcrystalline-quartz cemented, greensand with pore-filling berthierine of about $4.7 \%$.
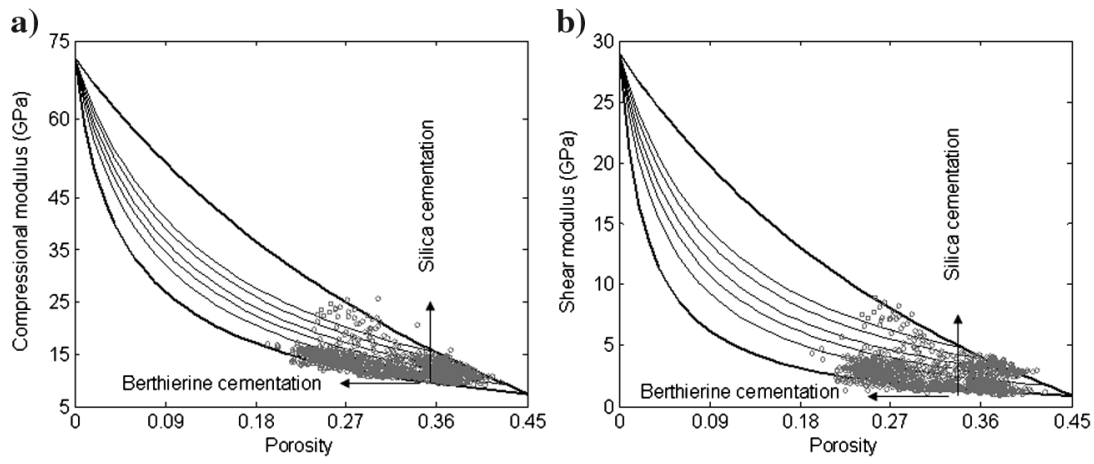

a)

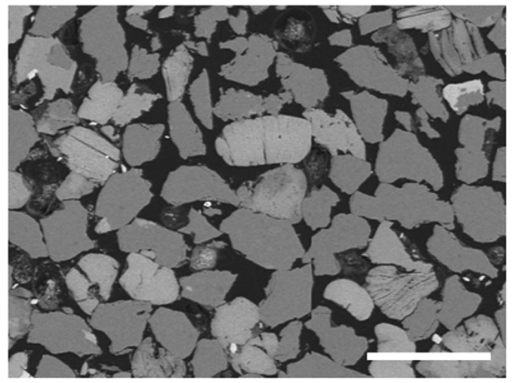

c)

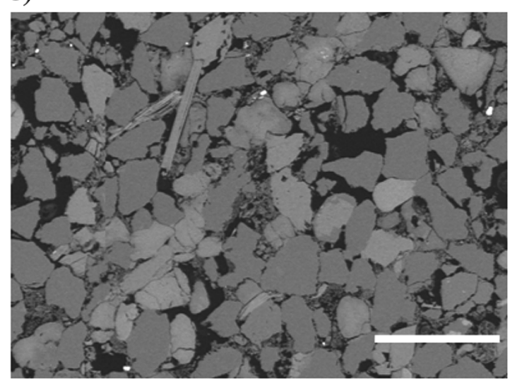

b)

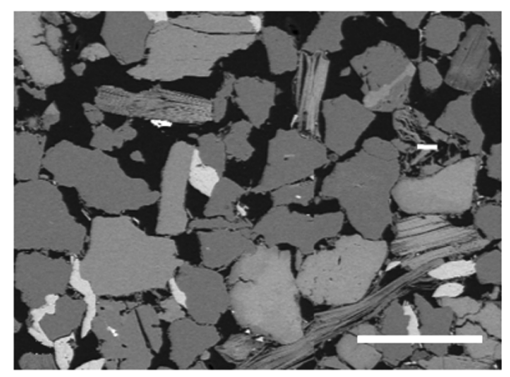

d)

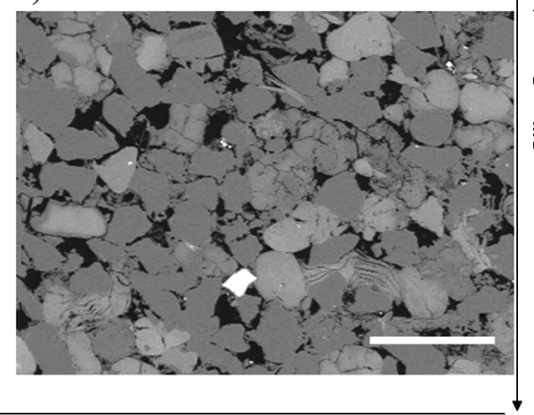

Berthierine cementation

Figure 10. Micrographs of microcrystallinequartz and berthierine-cemented greensand samples. (a) BSE image of silica linings on grains (arrowed). Quartz (Q), glauconite (Gl), and feldspar (F). (b) BSE image of berthierine-cemented greensand (arrowed). Quartz (Q) and glauconite (Gl). (Images modified after Stokkendal et al., 2009). a)

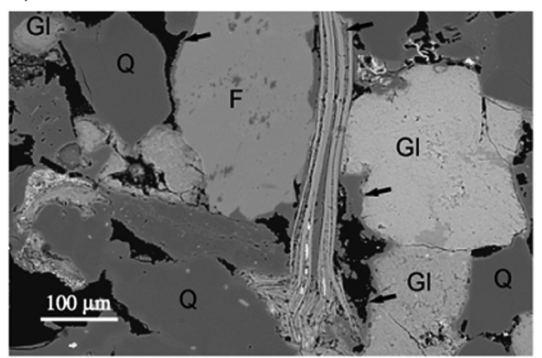

b)

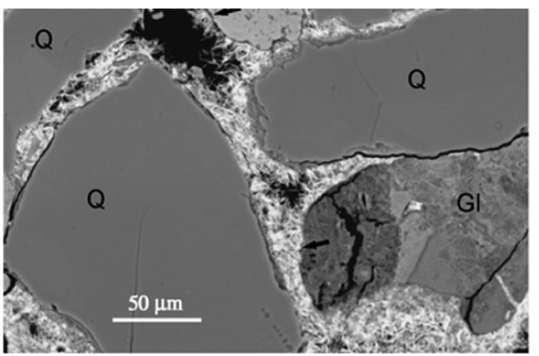


weakly or strongly cemented. Also, if such textural changes are not properly identified, seismic data may be misinterpreted. Based on laboratory data, log data, and thin-section analysis, we present a schematic rock-physics model of the North Sea greensand. This model is subdivided into several parts (Figure 12):

1. Depositional stage: During the deposition of greensand, quartz and glauconite grains are packed together. In clean greensand, where no diagenetic processes have occurred, the elastic properties of greensand can be calculated by using the HertzMindlin contact model for two types of grains (Figure 4).

2.1. Lack of silica cementation: At first, the marginal parts of the reservoir may have received a major flux of silica from the Sele Formation located in the Siri Canyon in the North Sea (Stokkendal et al., 2009). The silica flux did not influence all parts of the greensand reservoir. For this reason, during this stage, some of the greensand remained unchanged compared to the depositional stage. Elastic properties of this kind of greensand can be calculated by using Hertz-Mindlin contact model for two types of grains (Figure 5).

2.2. Early silica cementation: The first diagenetic mineral to form in the greensand was probably the silica cement. Silica may have formed as an opal rim so that the opal-derived microcrystalline quartz covers all grains. Microcrystalline quartz derived from the opal coating on detrital grains are found in close contact between grains, so this quartz cement has a stiffening effect on the elastic properties of the greensand. The elastic properties of this type of greensand can be calculated from the Hertz-Mindlin contact model by increasing
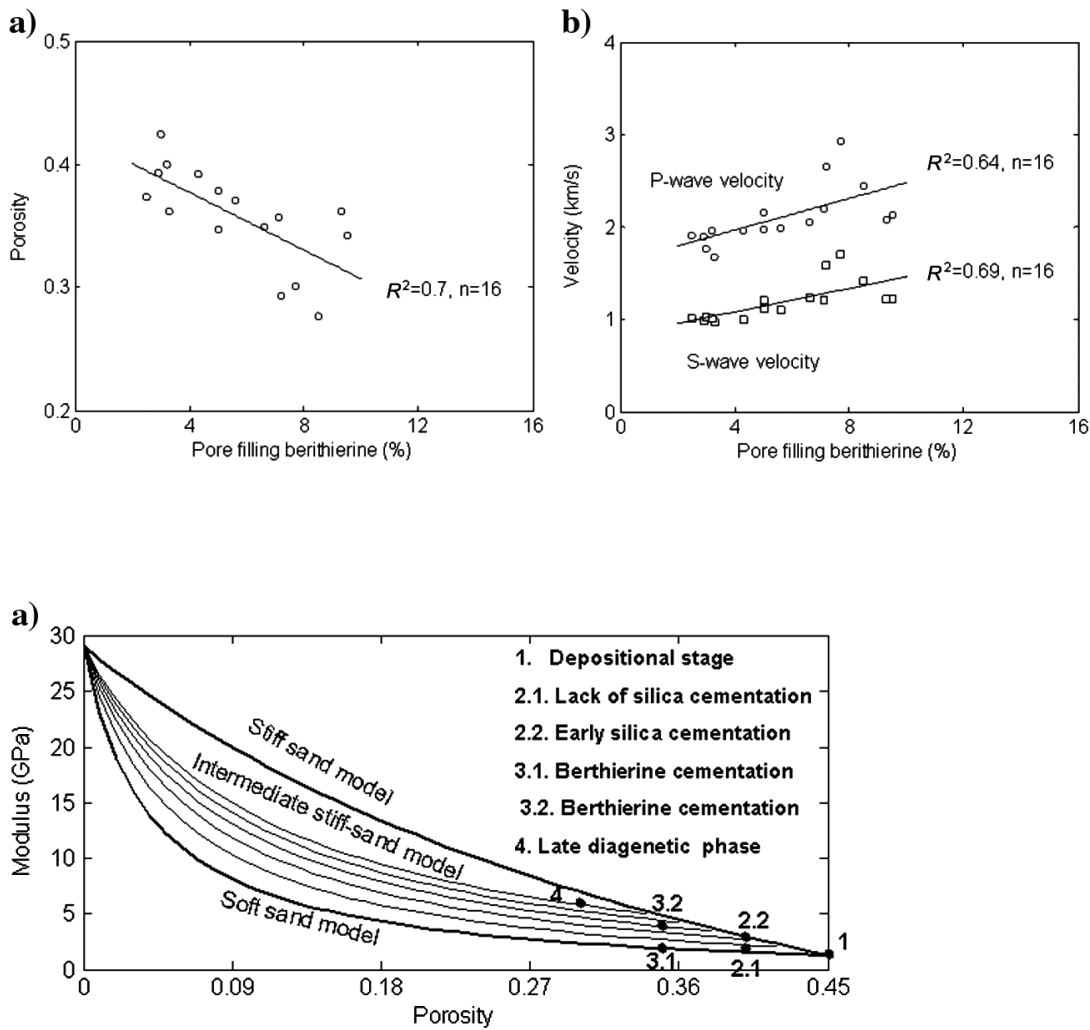

b)
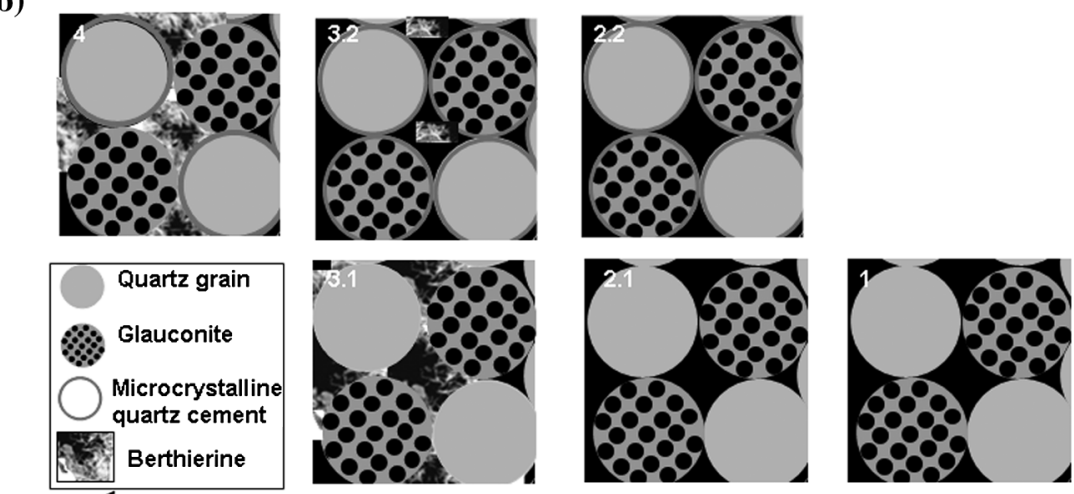

Late diagenetic phase Berthierine
Figure 11. (a) Correlation between pore-filling berthierine and Helium porosity and (b) correlation between pore-filling berthierine with laboratory measured sonic velocity. Pores-filling berthierine determined by point counting of thin sections, obtained from Solymar (2002).

Figure 12. Schematic rock-physics model for the North Sea greensand shows the link between rockphysics model and greensand diagenesis. 
the artificial coordination number (Figure 6). Elastic properties of this kind of greensand may be modeled by an intermediate-stiff-sand or a stiff-sand model.

3.1. Pore-filling berthierine cementation: In the greensand reservoir, where microcrystalline-quartz cement is absent, berthierine precipitates between the grains, so porosity of this kind of greensand decreases from the initial sand-pack porosity. This kind of greensand can be modeled by a softsand model.

3.2. Berthierine in early silica-cemented greensand: Berthierine also precipitates in greensand, where microcrystalline-quartz cement is present. Berthierine precipitation between the grains causes major porosity reduction. Elastic properties of this kind of greensand may be modeled by an intermediate-stiff-sand or a stiff-sand model.

4. Late diagenetic phase: If berthierine continues its growth in the pore space, the elastic properties of this kind of greensand may be modeled by an intermediate-stiff-sand or a stiff-sand model.

\section{CONCLUSION}

Calculated velocity for mixtures of quartz and glauconite from the Hertz-Mindlin contact model for two types of grains are higher than velocity calculated from the Hertz-Mindlin single mineral model using the effective mineral moduli predicted from the Hill's average.

Results of rock-physics modeling and thin-section observations indicate that variations in elastic properties of greensand can be explained by two main diagenetic phases: silica cementation and berthierine cementation. These diagenetic phases dominate in different parts of reservoir bodies.

Initially, greensand is a mixture of quartz and glauconite grains; when weakly cemented, it has relatively low elastic moduli and can be modeled by the Hertz-Mindlin contact model for two types of grains.

Silica-cemented greensand has relatively high elastic moduli and can be modeled by an intermediate-stiff-sand or stiff-sand model. Berthierine cement has a different growth pattern in the greensand formations, resulting in a soft-sand model and an intermediatestiff-sand model.

\section{ACKNOWLEDGMENTS}

We acknowledge the Stanford Rock-Physics laboratory and the department of Energy Resources Engineering, Stanford University, for their hospitality in summer 2009. Gary Mavko (Stanford University) is kindly acknowledged for his discussion on this work. Mikael Solymar is acknowledged for recording the BSE images. DONG Energy A/S is acknowledged for financial support.

\section{REFERENCES}

Avseth, P., 2000, Combining rock physics and sedimentology for seismic reservoir characterization of North Sea turbidite systems: Ph.D. thesis, Stanford University.

Avseth, P., T. Mukerji, and G. Mavko, 2005, Quantitative seismic interpretation: Applying rock physics tools to reduce interpretation risk: Cambridge University Press.

Bachrach, R., J. Dvorkin, and A. Nur, 2000, Seismic velocities and Poisson's ratio of shallow unconsolidated sands: Geophysics, 65, 559-564.

Batzle, M., and Z. Wang, 1992, Seismic properties of pore fluids: Geophysics, 57, 1396-1408.
Cagatay, M. N., S. Saner, I. Al-Saiyed, and W. J. Carrigan, 1996, Diagenesis of the Safaniya Sandstone member (mid-Cretaceous) in Saudi Arabia: Sedimentary Geology, 105, 221-239.

Coste, C., and B. Gilles, 1999, On the validity of Hertz contact law for granular material acoustics: European Physical Journal B: Condensed Matter Physiques, 7, 1, 155-168.

De Gennes, P., 1996, Static compression of a granular medium, the soft shell model: Europhysics Letters, 35, no. 2, 145-149.

Diaz, E., M. Prasad, G. Mavko, and J. Dvorkin, 2003, Effect of glauconite on the elastic properties, porosity, and permeability of reservoir rocks: The Leading Edge, 22, 42-45.

Digby, P. J., 1981, The effective elastic moduli of porous granular rocks: Journal of Applied Mechanics and Technical Physics, 48, 803-808

Dutta, T., 2009, Integrating sequence stratigraphy and rock-physics to interpret seismic amplitudes and predict reservoir quality: Ph.D. thesis, Stanford University.

Dvorkin, J., and A. Nur, 1996, Elasticity of high-porosity sandstones: Theory for two North Sea datasets: Geophysics, 61, 1363-1370.

Gassmann, F., 1951, Uber die elastizitat poroser medien: Veirteljahrsschrift der Naturforschenden Gesellschaft, 96, 1-23.

Goddard, J. D., 1990, Nonlinear elasticity and pressure-dependent wave speeds in granular media: Proceedings of the Royal Society of London, Series A, Mathematical and Physical Sciences, 430, 1878, $105-131$.

Han, D., 1986, Effects of porosity and clay content on acoustic properties of sandstones and unconsolidated sediments: Ph.D. thesis, Stanford University.

Hashin, Z., and S. Shtrikman, 1963, A variational approach to the elastic behavior of multiphase materials: Journal of Mechanics and Physics Solids, 11, 2, 127-140.

Hill, R., 1952, The elastic behavior of crystalline aggregate: Proceedings of the Physical Society of London, A65, 349-354.

Hossain, Z., I. L. Fabricius, and H. F. Christensen, 2009, Elastic and nonelastic deformation of greensand: The Leading Edge, 28, 260-262.

Hossain, Z., I. L. Fabricius, A. C. Grattoni, and M. Solymar, 2011b, Petrophysical properties of greensand as predicted from NMR measurements: Petroleum Geoscience, 17, 2, 111-125.

Hossain, Z., T. Mukerji, and I. L. Fabricius, 2011a, Vp-Vs relationship and amplitude variation with offset modeling of glauconitic greensand: Geophysical Prospecting, 61, 793-812.

Jenkins, J., D. Johnson, L. La Ragione, and H. Makse, 2005, Fluctuations and the effective moduli of an isotropic, random aggregate of identical, frictionless spheres: Journal of the Mechanics and Physics of Solids, 53, 197-225.

Johnson, K. L., 1985, Contact mechanics: Cambridge University Press.

Makse, A., N. Gland, D. Johnson, and L. Schwartz, 2004, Granular packings: Nonlinear elasticity, sound propagation, and collective relaxation dynamics: Physical Review E, 70, 6, 061302.

Marion, D., 1990, Acoustical, mechanical and transport properties of sediments and granular materials: Ph.D. thesis, Stanford University.

Mavko, G., T. Mukerji, and J. Dvorkin, 2009, The rock physics handbook: Tools for seismic analysis of porous media (2nd ed.): Cambridge University Press.

Mindlin, R. D., 1949, Compliance of elastic bodies in contact: Journal of Applied Mechanics and Technical Physics, 16, no. 3, 259-268.

Murphy, W. F., 1982, Effects of microstructure and pore fluids on the acoustic properties of granular sedimentary materials: Ph.D. thesis, Stanford University.

Norris, A. N., and D. L. Johnson, 1997, Non-linear elasticity of granular media: Journal of Applied Mechanics and Technical Physics, 64, 39-49.

Ranganathan, V., and R. S. Tye, 1986, Petrography, diagenesis, and facies controls on porosity in shannon sandstone, hartzog draw field, Wyoming: AAPG Bulletin, 70, 56-69.

Sain, R., 2010, Numerical simulation of pore-scale heterogeneity and its effects on elastic, electrical and transport properties: Ph.D. thesis, Stanford University.

Schiøler, P., J. Andsbjerg, O. R. Clausen, G. Dam, K. Dybkjær, L. Hamberg, C. Heilmann-Clausen, E. P. Johannessen, L. E. Kristensen, and I. Prince, 2007, Lithostratigraphy of the paleocene: Lower neogene succession of the Danish North Sea: Geological Survey of Denmark and Greenland Bulletin, 12.

Slot-Petersen, C., T. Eidsemo, J. White, and H. G. Rueslatten, 1998, NMR formation evaluation application in a complex low resistivity hydrocarbon reservoir: Transactions of the SPWLA 39th Annual Logging Symposium, Paper 1998-TT.

Solymar, M., 2002, Influence of composition and pore geometry on immiscible fluid flow through greensand: Ph.D. thesis, Chalmers University of Technology.

Solymar, M., I. L. Fabricius, and M. F. Middleton, 2003, Flow characterization of glauconitic sandstones by interated dynamic neutron radiagraphy and image analysis of backscattered electron micrographs: Petroleum Geoscience, 9, no. 2, 175-183. 
Stokkendal, J., H. Friis, J. B. Svendsen, M. L. K. Poulsen, and L. Hamberg, 2009 , Predictive permeability variations in a hermod sand reservoir, stine segments, Siri Field, Danish North Sea: Marine and Petroleum Geology, 26, 397-415.

Tilley, B. J., and F. J. Longstaffe, 1984, Controls on hydrocarbon accumulation in glauconitic sandstone, suffield heavy oil sands, southern Alberta: AAPG Bulletin, 68, 1004-1023.

Walton, K., 1987, The effective elastic moduli of a random pack of spheres: Journal of the Mechanics and Physics of Solids, 35, 213-226.
Wang, Z and A. Nur, 1992, Seismic and acoustic velocities in reservoir rocks: SEG Geophysics Reprint Series 10.

Winn, R. D., 1994, Shelf sheet-sand reservoir of the lower cretaceous greensand, North Celtic Sea Basin, offshore Ireland: AAPG Bulletin, 78, $1775-1789$.

Zimmer, M., 2003, Seismic velocities in unconsolidated sands: Measurements of pressure, sorting, and compaction effects: Ph.D. thesis, Stanford University. 